\section{RMD Open}

Rheumatic \&

Musculoskeletal Diseases

To cite: Lems WF.

Glucocorticoids: bad or safe for the bones?. RMD Open 2015:1:e000050.

doi:10.1136/rmdopen-2015000050

- Prepublication history for this paper is available online. To view these files please visit the journal online (http://dx.doi.org/10.1136/ rmdopen-2015-000050).

Received 2 February 2015 Revised 25 February 2015 Accepted 5 March 2015

\section{CrossMark}

Department of Rheumatology, VU University Medical Centre, Amsterdam, The Netherlands

Correspondence to Professor Willem F Lems; wf.lems@vumc.nl

\title{
Glucocorticoids: bad or safe for the bones?
}

\author{
Willem F Lems
}

\section{ABSTRACT}

Until recently, patients with rheumatoid arthritis (RA) were treated with monotherapy using conventional drugs such as sulfasalazine, antimalarials, intramuscular gold and methotrexate, which often leads to persistent arthritis, loss of functional capacity and decreased quality of life. The use of high-dose glucocorticoids (GCs) and active RA are both associated with generalised bone loss and fractures, while GCs have a strong immunosuppressive effect. With the introduction of very effective tumour-necrosis factor-blockers and other biologics, clinical remission is a realistic target in around half of the early patients with RA; the same appears true for the use of methotrexate with chronic low dose or initially highdose GCs. With the use of a treat-to-target strategy focusing on clinical remission or low disease activity in early patients with RA, the negative effects of systemic inflammation on bone can be inhibited and local bone loss (in the joints), and generalised bone loss at the spine and hips, can be limited or prevented. Whether this also leads to a reduction in vertebral and nonvertebral fractures remains to be demonstrated. Another issue is, in other systemic rheumatic diseases in which treatment options are smaller and less effective than in RA, local and systemic bone loss may still occur.

\section{ACTIVE RHEUMATOID ARTHRITIS AND BONE LOSS}

In the past, patients with rheumatoid arthritis (RA) were treated with conventional diseasemodifying antirheumatic drugs (DMARD)monotherapy, resulting in joint erosion and cartilage loss in many patients, and, as a consequence, loss of functional capacity and quality of life. ${ }^{1}$ Apart from local bone loss around the joints, generalised bone loss was also observed: a twofold increase in the prevalence of osteoporosis, defined as a T-score $<-2.5$, was found in a large, cross-sectional study in Norway in female patients with RA versus healthy controls, matched for age and gender. ${ }^{2}$ In 1994, before the introduction of biologics and combination therapy of conventional DMARDs, an observational study in early RA was published in which high-bone loss was observed after 2 years: $-2.4 \%$ at the spine and $-4.3 \%$ at the hip. ${ }^{3}$ In a subgroup analysis, bone loss in the spine as well as in the hips was, after 1 year, much greater in those patients with high $\mathrm{C}$ reactive protein (CRP)-levels $(>20 \mathrm{mg} / \mathrm{dL})$ than in those patients with low CRP-levels $(<20 \mathrm{mg} / \mathrm{dL})$, for example, in the spine: $-2.1 \%$ vs $0.2 \%$, respectively. The same was found in the lumbar spine for patients with low functional capacity (HAQ-score $>1$ ) compared to patients with a better HAQ-score $(<1):-1.9 \%$ vs $-0.2 \%$, respectively. In a crosssectional study in 2003 in three European countries (Norway, UK and the Netherlands), it was shown that chronic joint inflammation in chronic patients with RA, estimated by the Larsen radiological joint damage score, is associated with low bone mineral density (BMD) as well as with vertebral deformities. ${ }^{4}$

However, generalised bone loss is usually asymptomatic; the clinical relevance of elevated bone loss is that it is associated with a higher fracture risk. In line with that, the risk of a having a vertebral fracture was doubled in chronic patients with RA versus healthy controls, matched for age, gender and social background. ${ }^{5}$ In addition, the risk of the so-called peripheral or non-vertebral fractures was also elevated (roughly double), in chronic patients with RA. ${ }^{6}$

Thus, data from 10 to 20 years ago show that chronic, suboptimally treated RA is associated with both local and generalised bone loss, leading to joint deformations, and vertebral and non-vertebral fractures. Osteoporosisrelated fragility fractures represent one of the most important extra-articular complications that may occur in patients with RA; obviously, these fractures may contribute to an important decrease in quality of life. High-disease activity (inflammation), immobility and treatment with glucocorticoids (GCs) are the main factors that increase the risk of osteoporotic fractures, on top of the background fracture 
risk based on, among others, high age, low body mass and female gender. ${ }^{7}$

Recent data in the field of osteoimmunology have documented two phases in the pathogenesis of RA: an early, autoimmune phase, in which environmental factors such as smoking play a role in susceptible patients, as well as rheumatoid factor and anticitrullinated proteins (ACPA), of which the latter may have an independent (stimulating) effect on osteoclasts. ${ }^{8}$ In the second period, the inflammatory phase, it has been elucidated that by the crosstalk between cytokines and bone, activated inflammatory cells at sites of inflammation produce a wide spectrum of cytokines that stimulate local and generalised bone resorption, modulated by changes in receptor activator for nuclear factor- $\mathrm{kB}$ ligand (RANKL) and osteoprotegerin (OPG), and also interfere with the Wnt-signalling pathway, resulting in inhibited bone formation in patients with $\mathrm{RA} ;{ }^{9}{ }^{10}$ the combination of upregulated bone resorption with depressed bone formation might be hazardous to bone strength.

\section{GLUCOCORTICOIDS AND BONE}

Early studies on the pathogenesis of glucocorticoidinduced osteoporosis (GIOP) were performed in patients treated with high-dose GCs. In these histomorphometric studies, reduced bone formation, characterised by a low mineral apposition rate (which is related to a reduction in the number of osteoblasts) was found, while bone resorption was unchanged or even elevated. ${ }^{11}$ During the past few years, several studies have provided more insight into the molecular mechanisms involved in the pathogenesis of GIOP. These mechanisms include GC-induced increased apoptosis of mature osteoblasts and osteocytes, impaired differentiation of osteoblasts, which results in reduced bone formation and an increase in the life span of osteoclasts. In addition, the loss of osteocytes is supposed to induce a disrupted osteocyte-canalicular network and failure to respond to bone damage, ${ }^{12}$ which may lead to reduced bone strength. GCs have been demonstrated to suppress the Wnt-pathway by stimulating the production of Wnt pathway inhibitors, such as dickkopf-1 (Dkk-1) and sclerostin. ${ }^{13} 14$ In addition, GCs stimulate bone marrow stromal cells to differentiate toward adipocytes instead of osteoblasts. GCs induce an increased life span of osteoclasts as a consequence of an upregulation of RANKL and suppression of (OPG) ${ }^{15}$

The increased risk for fractures during GC treatment appears to be dose-dependent. ${ }^{16}{ }^{17}$ Van Staa demonstrated that hip fracture risk in patients taking a standardised daily dose of less than $2.5 \mathrm{mg}$ prednisolone was $0.99(0.82-1.20)$, rising to $1.77(1.55-2.02)$ at daily doses of 2.5-7.5 mg and $2.27(1.94-2.66)$ at doses of $7.5 \mathrm{mg}$ or greater. ${ }^{17}$ The relative risk of vertebral fractures is particularly elevated during GC treatment and ranges from $1.55(1.20-2.01)$ in patients using less than $2.5 \mathrm{mg}$ prednisolone daily up to $5.18(4.25-6.31)$ in patients treated with more than $7.5 \mathrm{mg}$ of prednisone per day. ${ }^{17}$ After discontinuation of GC treatment, the fracture risk gradually returns to baseline and is therefore supposed to be partially reversible. ${ }^{18}$ Besides GC dose, age, female gender, fall history, previous fractures, low body mass index, smoking, immobility and the activity of the underlying disease, also influence fracture risk. ${ }^{19}$

Despite the apparent effect of GC use on bone density, GC-induced changes in BMD do not fully account for the increased fracture risk in GC-treated patients. An adverse effect of GCs on bone quality is supposed to further increase the risk of fractures, which leads to a so-called 'reduced bone density threshold for vertebral fractures'.$^{20}$ Data from two randomised controlled trials demonstrated a significantly increased incidence of vertebral fractures after a follow-up of 1 year in patients treated with GCs compared to non-users, despite higher BMD values in the GC-treated patients. ${ }^{21}$ This phenomenon might be explained by an increased risk of falling due to steroid-induced muscle weakness and frailty, and by changes in the bone architecture that were not captured by (two-dimensional) BMD measurements with dual-energy X-ray absorptiometry. ${ }^{22}$

\section{MODERN TREATMENT OF RA}

The pathogenesis of RA is still incompletely understood, but thought to be multifactorial, involving multiple genes, environmental triggers and chance. ${ }^{23}$ The disease is currently classified on the basis of the clinical phenotype; maybe it is possible in the near future to define different disease subgroups with different prognosis. ${ }^{23}$

With the use of biologics, preferably in combination with methotrexate (MTX), it is possible to induce clinical remission in around $50 \%$ of early patients with RA. The number of biologics has been gradually increasing over the years, and currently consists of five TNF-blocking agents, rituximab (a B-cell blocker), T-cell-interaction blockade (abatacept) and interluekin 6 (IL-6) blockade (tocilizumab). Without any doubt, the introduction of these biologics has brought an enormous step forward in the treatment of RA. ${ }^{24-26}$ However, the cost price of these drugs is high, and infection risk is elevated.

One of the possibilities to get more insight into the complex pathogenesis of local and generalised bone loss in RA, the so-called osteoimmunology, ${ }^{27}$ is to investigate the powerful effects of modern treatment of RA with tumour-necrosis factor (TNF)-blocking agents and other biologics, on local and generalised bone loss in RA.

Although bone loss was substantial in earlier studies in patients with RA, we have recently shown that treatment with anti-TNF arrests BMD loss at the hip and the spine. In an open cohort study of 102 patients with RA from Norway and the Netherlands, all of whom were treated with infliximab and MTX, there was no bone loss at the spine and hip after 1 year, while BMD in patients with a 
good European League Against Rheumatism (EULAR) response showed a favourable change in BMD compared to patients not achieving such a response, indicating that adequately suppressing systemic inflammation in RA is beneficial for the prevention of generalised bone loss. ${ }^{28}$ Prevention of bone loss was also observed during 1 year of treatment with adalimumab, ${ }^{29}{ }^{30}$ and also during chronic (on average 3 years) treatment with infliximab and MTX. ${ }^{31}$ In patients with RA treated with rituximab, bone resorption markers decreased, while bone formation markers increased. ${ }^{32}$

During treatment with tocilizumab, more or less the same pattern was observed: no significant changes in BMD at the lumbar spine and hips, a decrease in serum DKK-1 and an increase in serum P1NP. ${ }^{33}$ However, no changes in serum CTX-1, a marker of collagen degradation, were observed, which is somewhat more difficult to interpret. ${ }^{33}$

\section{GCS IN RA: EFFECTS ON BONE}

One of the most intriguing questions within the field of rheumatology is the effect of the use of GCs in patients with RA on bone. As described, the use of GCs, and also active RA, might have a devastating effect on bone, but it is well-known that GCs have strong anti-inflammatory effects. In other words, is it possible to counteract the negative effects on bone by adequate suppression of systemic inflammation? ${ }^{34} 35$

This has been investigated in the BeSt study, a novel study design comparing four different treatment strategies in which treatment adjustments were made continuously when low disease activity, defined as disease activity score (DAS) <2.4, was not reached in patients with recent-onset RA. ${ }^{36}$ The treatment strategies were: group 1, sequential monotherapy starting with MTX; group 2, step-up combination therapy starting also with MTX; group 3, initial combination therapy with MTX, sulphasalazine and a quickly tapered high dose of prednisone (more or less the same as the conventional COBRA-scheme) $;{ }^{37}$ and group 4 , initial combination therapy with MTX and the TNF $\alpha$ (TNF- $\alpha)$ inhibitor infliximab. After 2 years of DAS-steered treat-to-target therapy, BMD decreased at the hips by $-1.1 \%$ (group 1 ),$-0.2 \%$ (group 2 ), $-0.2 \%$ (group 3 ) and $-0.6 \%$ (group 4 ). At the lumbar spine, the bone loss was $-0.4 \%,-1.6 \%,-0.5 \%$ and $-1 \%$, respectively. ${ }^{38}$ We concluded that generalised bone loss was limited in all four groups of patients and that the generalised bone loss was not higher in patients initially treated with high-dose prednisone. In addition, radiological joint damage was low in all four groups. This clearly suggests that the negative effect of GC on bone in early RA should be outweighed against the strong anti-inflammatory effects of GCs on bone. $^{9}$

The BeSt study was among the first modern treatto-target studies to show that the use of GCs may not be harmful to the bone in early RA. It is important to realise that the BeSt study was a DAS-steered treat-to-target study in which several predefined treatment options were prescribed to patients who do not have low disease activity; it was not a randomised controlled trial comparing the effects of prednisone versus placebo. Another issue is that no treat-to-target studies in chronic RA are available that demonstrate the arrest of local and generalised bone loss. Earlier, it was demonstrated that the use of $7.5 \mathrm{mg}$ prednisone per day versus placebo in addition to conventional DMARD-therapy, usually monotherapy at that time, prevents hand bone loss. ${ }^{39}$

However, it has recently been demonstrated that prednisone $10 \mathrm{mg}$ per day versus placebo in early patients with RA treated with MTX, following a treat-to-target strategy, has a positive effect not only on disease activity, but also on local bone loss (as measured by the Sharp van der Heijden radiological joint score ${ }^{40}$ ). This raises the question of whether generalised bone loss at the spine and hips could be prevented in these patients. Since the authors thought it was unethical not to prescribe antiosteoporotic drugs in high-risk patients, they prescribed calcium and vitamin $\mathrm{D}$ to all patients and, additionally, bisphosphonates to patients at high risk for fractures. ${ }^{41}$ Following that regimen, no bone loss was found at the lumbar spine and at the hips and no difference between the groups.

Nevertheless, bone mineral density is not the same as bone quality: some aspects of bone quality, for example, connectivity of trabeculae, are not captured in BMD measurements. In four large administrative databases, it was found that the risk of fractures did not differ between around 13500 patients treated with biologics and patients treated with non-biologics. ${ }^{42}$ In another study, a comparison was made between nearly 6000 patients with RA treated with anti-TNF, 12500 MTX users and 7500 patients with RA treated with other antirheumatic drugs: no difference in fracture rate was found between the groups. ${ }^{43}$ Since biologics are usually prescribed in patients with high levels of inflammation, and thus with a higher baseline fracture risk, the absence of a difference or an increase in fracture risk can be regarded as in line with the concept that biologics have bone protecting effects in patients with systemic inflammation.

\section{SUMMARY}

Earlier data have shown that active RA, and also the use of high-dose GCs, are associated with bone loss, and vertebral and non-vertebral (including hip) fractures. At that time, local bone destruction was associated with decreased functional capacity in many patients with RA, and the increased fracture rate was regarded as a clinically relevant comorbidity.

However, with the combined use of biologics and MTX or with low-dose GCs or initial high-dose GCs combined with MTX, it is possible to induce clinical remission or low disease activity in around $50 \%$ of patients. As a consequence, it appears that local and generalised bone loss in RA can be prevented. 
Whether this also has an effect on bone strength and leads to a reduction in vertebral and non-vertebral fractures in RA remains to be demonstrated. Another issue is that in other systemic rheumatic diseases in which treatment options are smaller and less effective than in RA, local and systemic bone loss may still occur.

Competing interests None declared.

Provenance and peer review Commissioned; externally peer reviewed.

Data sharing statement No additional data are available.

Open Access This is an Open Access article distributed in accordance with the Creative Commons Attribution Non Commercial (CC BY-NC 4.0) license, which permits others to distribute, remix, adapt, build upon this work noncommercially, and license their derivative works on different terms, provided the original work is properly cited and the use is non-commercial. See: http:// creativecommons.org/licenses/by-nc/4.0/

\section{REFERENCES}

1. Drossaers-Bakker KW, de Buck M, van Zeben D, et al. Long-term course and outcome of functional capacity in RA: the effect of disease activity and radiological damage over time. Arthritis Rheum 1999;42:1854-60.

2. Haugeberg G, Uhlig T, Falch JA, et al. Bone mineral density and frequency of osteoporosis in female patients with rheumatoid arthritis. Arthritis Rheum 2000;43:522-30.

3. Gough AK, Lilley J, Eyre S, et al. Generalised bone loss in patients with early rheumatoid arthritis. Lancet 1994;(8914):23-7.

4. Lodder MC, Haugeberg G, Lems WF, et al, Oslo-Truro-Amsterdam (OSTRA) Collaborative Study. Radiographic damage associated with low bone mineral density and vertebral deformities in rheumatoid arthritis: the Oslo-Truro-Amsterdam (OSTRA) collaborative study. Arthritis Rheum 2003;49:209-15.

5. Ørstavik RE, Haugeberg G, Mowinckel P, et al. Vertebral deformities in rheumatoid arthritis: a comparison with population-based controls. Arch Intern Med 2004;164:420-5.

6. van Staa TP, Geusens P, Bijlsma JW, et al. Clinical assessment of the long-term risk of fracture in patients with rheumatoid arthritis. Arthritis Rheum 2006;54:3104-12.

7. Vis M, Guler-Yuksel M, Lems WF. Can bone loss in rheumatoid arthritis be prevented? Osteoporosis Int 2013;(10):2541-53.

8. Kleyer A, Finzel S, Rech J, et al. Bone loss before the clinical onset of RA in subjest with ACPA. Ann Rheum Dis 2014;73:854-60.

9. Schett G, Saag KG, Bijlsma JW. From bone biology to clinical outcome: state of the art and future perspectives. Ann Rheum Dis 2010;69:1415-19.

10. Geusens P, Lems WF. Osteoimmunology and osteoporosis. Arthritis Res Ther 2011;13:242.

11. Weinstein RS, Jilka RL, Parfitt AM, et al. Inhibition of osteoblastogenesis and promotion of apoptosis of osteoblasts and osteocytes by glucocorticoids. Potential mechanisms of their deleterious effects on bone. J Clin Invest 1998;102:274-82.

12. O'Brien CA, Jia D, Plotkin L, et al. Glucocorticoids act directly on osteoblasts and osteocytes to induce their apoptosis and reduce bone formation and strength. Endocrinology 2004;145:1835-41.

13. Ohnaka K, Tanabe M, Kawate $\mathrm{H}$, et al. Glucocorticoid suppresses the canonical Wnt signal in cultured human osteoblasts. Biochem Biophys Res Commun 2005;329:177-81.

14. Wang FS, Ko JY, Yeh DW, et al. Modulation of Dickkopf-1 attenuates glucocorticoid induction of osteoblast apoptosis, adipocytic differentiation, and bone mass loss. Endocrinology 2008;149:1793-801.

15. Hofbauer LC, Gori F, Riggs BL, et al. Stimulation of osteoprotegerin ligand and inhibition of osteoprotegerin production by glucocorticoids in human osteoblastic lineage cells: potential paracrine mechanisms of glucocorticoid-induced osteoporosis. Endocrinology 1999;140:4382-9.

16. Cooper C, Coupland C, Mitchell M, et al. Rheumatoid arthritis, corticosteroid therapy and hip fracture. Ann Rheum Dis 1995;54:49-52.

17. van Staa TP, Leufkens HG, Abenhaim L, et al. Use of oral corticosteroids and risk of fractures. J Bone Miner Res 2000;15:993-1000.

18. De Vries F, Bracke M, Leufkens HG, et al. Fracture risk with intermittent high-dose oral glucocorticoid therapy. Arthritis Rheum 2007;56:208-14.
19. Kanis JA, Borgstrom F, de Laet $\mathrm{C}$, et al. Assessment of fracture risk. Osteoporos Int 2005;16:581-9.

20. Lems WF. Bisphosphonates and glucocorticoids: effects on bone quality. Arthritis Rheum 2007:56:3518-22.

21. van Staa TP, Laan RF, Barton IP, et al. Bone density threshold and other predictors of vertebral fracture in patients receiving oral glucocorticoid therapy. Arthritis Rheum 2003;48:3224-9.

22. Weinstein RS. Clinical practice. Glucocortcoid-induced bone disease. New Engl J Med 2011;365:62-70.

23. Mc Innes IB, Schett $\mathrm{G}$. The pathogenesis of rheumatoid arthritis. New Engl J Med 2011:2205-19.

24. Klareskog L, Catrina A, Paget S, et al. Therapeutic effect of the combination of etanercept and methotrexate compared with each treatment alone in patients with rheumatoid arthritis: double-blind randomised controlled trial. Lancet 2004;363:675-81.

25. Maini RN, Breedveld FC, Kalden JR, et al. Sustained improvement over two years in physical function, structural damage, and signs and symptoms among patients with rheumatoid arthritis treated with infliximab and methotrexate. Arthritis Rheum 2004;50:1051-65.

26. Weinblatt ME, Keystone EC, Furst DE, et al. Adalimumab, a fully human anti-tumor necrosis factor alpha monoclonal antibody, for the treatment of rheumatoid arthritis in patients taking concomitant methotrexate: the ARMADA trial. Arthritis Rheum 2003;48:35-45.

27. Takayanagi $\mathrm{H}$. Osteoimmunology and the effects of the immune system on bone. Nat Rev Rheumatol 2009;5:667-76.

28. Wheater G, Honig VE, Teng YK, et al. Suppression of bone turnover by $\mathrm{B}$-cell depletion in patients with rheumatoid arthritis. Osteoporos Int 2011;22:3067-72.

29. Vis M, Havaardsholm EA, Haugeberg G, et al. Evaluation of bone mineral density, bone metabolism, osteoprotegerin and receptor activator of the NFkappaB ligand serum levels during treatment with infliximab in patients with rheumatoid arthritis. Ann Rheum Dis 2006;65:1495-9.

30. Wijbrandts CA, Klaasen R, Dijkgraaf MG, et al. Bone mineral density in rheumatoid arthritis patients 1 year after adalimumab therapy: arrest of bone loss. Ann Rheum Dis 2009;68:373-6.

31. Krieckaert CL, Nurmohamed MT, Wolbink G, et al. Changes in bone mineral density during long-term treatment with adalimumab in RA-patients: a cohort study. Rheumatology 2013;52:547-53.

32. Eekman DA, Vis M, Bultink IE, et al. Stable bone mineral density in lumbar spine and hip in contrast to bone loss in the hands during long-term treatment with infliximab in patients with rheumatoid arthritis. Ann Rheum Dis 2011;70:389-90.

33. Briot K, Schaeverbeke T, Etchepare F, et al. Positive effects of tocilizumab on bone remodelling in patients with RA. Arthritis Rheum 2012;64(Suppl 10):823.

34. Bijlsma JWG, Boers M, Saag KG, et al. Glucocorticoids in the treatment of early and late RA. Ann Rheum Dis 2003;62:1033-7.

35. Smolen JS, Landewe R, Breedveld FC, et al. EULAR recommendations for the management of rheumatoid arthritis with synthetic and biological disease-modifying antirheumatic drugs: 2013 update. Ann Rheum Dis 2014;73:492-509.

36. Goekoop-Ruiterman YPM, De Vries-Bouwstra JK, Allaart CF, et al. Clinical and radiographic outcomes of four different treatment strategies in patients with early rheumatoid arthritis (the BeSt study): a randomized, controlled trial. Arthritis Rheum 2005;52:3381-90.

37. Boers M, Verhoeven AC, Markusse HM, et al. Randomised comparison of combined step-down prednisolone, methotrexate and sulphasalazine with sulphasalazine alone in early rheumatoid arthritis. Lancet 1997;350:309-18.

38. Güler-Yüksel M, Bijsterbosch J, Goekoop-Ruiterman YP, et al. Changes in bone mineral density in patients with recent onset, active rheumatoid arthritis. Ann Rheum Dis 2008;67:823-8.

39. Haugeberg G, Starnd A, Kvien TK, et al. Reduced loss of bone density with prednisone in early RA, a randomized placebocontrolled trial. Arch Int Med 2005;165:1293-7.

40. Bakker MF, Jacobs JW, Welsing PM, et al. Low-dose prednisone inclusion in a methotrexate-based, tight control strategy for early rheumatoid arthritis: a randomized trial. Ann Intern Med 2012;156:329-39.

41. Goes van der MC, Jacobs JWG, Jurgens MS, et al. Are changes in bone mineral density different between groups of early RA treated to a tight control strategy with or without prednsiolone if osteoporosis prophylaxis is applied? Ost Int 2013;24:1429-36.

42. Kawai VK, Grijalva CG, Arbogast PG, et al. Initiation of tumor necrosis factor $\alpha$ antagonists and risk of fractures with selected rheumatic and autoimmune diseases. Arthritis Care Res 2013;65:1085-94.

43. Kim SY, Schneeweiss S, Liu J, et al. Effects of disease-modifying antirheumatic drugs on nonvertebral fracture risk in RA. J Bone Miner Res 2012;27:789-96. 